Session 1664

\title{
Materials I: Creating a Common Ground of Basic Skills
}

\author{
Ed Gohmann \\ Purdue University Programs \\ New Albany, Indiana
}

\begin{abstract}
The Materials I course is the first MET course the freshman students take. A typical class is made up of students straight out of high school and students who have been out of high school for some time. All need to be put on a common ground as they have a wide variety and level of basic skills. This paper discusses what has been done over the years to address this disparity of skills.
\end{abstract}

\section{INTRODUCTION:}

Materials I is a first semester course taken by Mechanical Engineering Technology students. It is also required of the students pursuing a degree in Technical Graphics. And frequently it is taken by students who have bachelor's and master's degrees trying to upgrade their marketable skills. Thus the makeup of a typical class can range from students who have been out of high school 10-12 years, recently graduated students and those with various levels of college degrees. There are no prerequisites for this course other than acceptance into the MET or TG program. (see appendix I for entrance requirements) Frequently some students are also enrolled in remedial math and English courses to raise their proficiency in these areas.

To accommodate these varied backgrounds the course is geared to accepting the student skills as they are and by careful interaction with the student, to bring them up to university level learning skills by the end of the semester without sacrificing the technical content of the course.

Lab exercises are done to complement the lectures and to give the students first hand experience in setting up equipment, recording data and writing reports.

The content level of the course follows that of generally used text on materials technology. (appendix 3)

\section{OBJECTIVES}

The objectives of the course are:

1) Give students a firm background in metals, plastics and ceramics: properties, structure, types, heat treating, testing, applications and a basis for further study. 
2) Develop ability to write technical memos and reports with clear concise grammar and correct spelling and composition.

3) Give introduction to preparing and presenting technical talks.

4) Afford opportunity to develop teamwork skills.

5) Afford opportunity to learn skills in measuring and recording data.

7. Introduction to physical applications of basic mathematics.

\section{COMMUNICATIONS:}

All the students admitted to the MET program are given English placement tests if they have not already passed a freshman composition course. As a result about $50 \%$ of the class will be enrolled in a remedial English course during their first semester along with the Materials I class. Putting them in the Materials class has the effect of stimulating their interest in developing good writing skills. At the same time a typical class attracts students with B.S. or above degrees who want to expand their job skills. Degrees at this level usually assure adequate writing skills but not necessarily in a technical field.

The class is conducted assuming minimal writing skills, thus many errors in grammar and spelling are expected and realized. Heavy emphasis is put on assignments such as a report on the nature of corrosion. Students are given examples of a bibliography which includes textbooks, journals, periodicals, and encyclopedias. The lack of a bibliography in proper form can detract as much as 5\% off the grade of an otherwise well written paper. Grading, spelling, and grammar on all papers focuses the students attention on the importance of good technical writing skills.

The most common grammar errors are sentences with no subject and/or predicate and the frequent use of the words "is where" or "is when." Some sentences are so poorly constructed that the meaning is obscured. In the event of such a paper an individual conference is held with the student and examples of correct wording are given.

Early attempt to have the students begin with formal lab reports ended with mixed results such as having the procedure written as the conclusion. Having the first half dozen labs reported as memos stating what was done, why it was done and what the results and conclusions were yielded better results. One or two formal labs reports are required toward the end of the semester after writing skills have had a chance to improve.

The other area of communication emphasized is oral presentation of technical material. Early in the semester students are called on individually to explain some topic, in their own words, which has been covered in the lecture or reading assignment. All too frequently the student strings together technical terms in such a way as to have no meaning. It is emphasized that all students are called upon and, even with the possibility of personal embarrassment, the response is good. The students realize that many in the class are in the same boat as they are. After the student 
responds to the question his/her errors are carefully made clear and a second attempt is given to rephrase the answer. This practice is continued each week throughout the semester. The culmination of the efforts to learn technical speaking is two assigned three minute talks on any subject covered in the course to the date of the talk. The vast majority of students have never given a talk before their peers, let alone a talk on technical subjects. The students are allowed to use notes but are cautioned that reading rotely from a prepared text will result in a decrease in their grade. Eye contact, visual aids and a good speaking voice are considered in the grade. The results range from a no note talk on the engineering stress-strain diagrams to giving up after a minute and a half.

Learning how to evaluate these talks required learning on the part of the instructor who was unsure of what to grade when these talks were included in the course. Over the years a brief grading form was developed with three main divisions: preparation, content, and delivery.

Preparation was judged by the use of note cards and/or visual aid. Rote reading from a prepared script is regarded with a maximum grade of $\mathrm{C}$, assuming the content was acceptable. The content is judged for proper use of technical terms and correct explanation of technical concepts.

(It becomes quickly apparent whether the student has copied from a resource or is putting the material in his own words.)

These talks take time from lecture material but the demand from employers for graduates who can write and speak in technical terms make the sacrifice worthwhile. With a typical class of 15 to 20 students each giving a three minute talk, (time is closely checked and the student stopped if they exceed three minutes) it takes 45 minutes to an hour. The usual lecture/lab time runs 100 minutes, two nights a week so time is left for critique by the instructor and the students.

It has been said that a student retains $10 \%$ of what they hear and $90 \%$ of what they do.

\section{$\underline{\text { LAB SKILLS }}$}

It is assumed that the students have either never had a physics or chemistry course or had such courses too long ago to be useful to them. None are assumed to have had, at anytime, college level physics or chemistry courses. The concepts of force, mass, heat and temperature are related to their personal interaction with the physical world, mainly on an intuitive level. During tensile tests on various metals they are given first hand experience in observing the effects of force on the physical dimensions of a tensile specimen. Mass is presented as the quantity of matter in an object which remains constant regardless of the gravitational field in which it is located. The concept of a standard of mass is presented along with standards of length and temperature. For most of the classes this is their first exposure to the fact of standards against which other various measurement are compared.

Usually they have all had first hand experience with weight and length, some even have experience with the metric system of weight and length. The necessary physical concepts for 
understanding properties of materials are taught at the level of a first year physics course for nonengineering majors.

The first two labs are designed so as to give all the students an equal level of lab skills. For instance the first lab involves determining the specific gravity of 8 objects by weighing and then measuring volume by displacement of water. It is a relatively crude lab but serves to orient the thinking of the student toward observing, measuring and recording data with a brief introduction to reflecting on the purpose and results of the lab.

The second lab does specific gravity by immersion in water and also includes an introduction to hardness testing stressing the use of manual hardness testers to improve hands-on skills.

Students must take turns using some of the equipment, this helps develop teamwork skills. By the end of the second lab the students are ready for more involved work such as tensile testing and the effects of heat treating.

Another topic that needs attention is the use of numbers. Most of the students have never given a physical meaning to a number except for length. Presenting such concepts as stress and strain before actually doing the laboratory work causes the majority of the students considerable consternation. Only after doing several tensile tests and the related calculations does the physical meaning of the numbers become understandable. Some of the laboratory work involves plotting graphs which is another unknown area for the students. Manually plotting stress-strain diagrams is emphasized as a learning tool which focuses the student's attention on the meaning of the data. Laboratory time is devoted to teaching how to select scales for the axes, plotting experimental data, labeling the axes and general neatness in manual drawing. Reading critical data points from the resulting graphs is required.

\section{SUMMARY:}

What follows is a brief summary of the methods used.

1. Exercise: Conduct beginning labs as if no student had ever done a lab exercise before at any level.

Objective: Give the students experience in setting up lab equipment, observing. Measuring recording and interpreting data.

Results: $\quad$ Students are eager to do hands on activities and work well together.

2. Exercise: Write beginning lab reports in the form of a memo citing what was done, why it was done, what the results were and what conclusions were drawn.

Objective: Develop technical writing skills including correct grammar, punctuation and spelling. 
Results: $\quad$ Most students do well in writing reports in this format. It gives them their first opportunity to do technical writing and have it corrected where necessary.

3. Exercise: Have the students give brief oral reports about the lab exercises. Evolve to presenting two three minute talks about any subject covered in the course.

Objective: Develop technical speaking skills.

Results: $\quad$ This is usually the first time that the technical content of their speech has been monitored and corrected. It takes the entire semester for some to develop technical speaking skills.

4. Exercise: As part of a lab session, follow a step by step procedure to prepare a graph manually.

Objective: Show that graphs can be a powerful way of presenting data.

Results: $\quad$ The plotting of data points is not a difficulty but the choice of scales for the axes takes some time to learn.

\section{CONCLUSIONS:}

No scientific study has been made of the effectiveness of this teaching procedure on the students skills. However some data on grades during the evolution of the course for the past 12 years is interesting. Prior to 1989 the course was taught as lecture only. There were no labs, no reports, some library assignments. For the five years, 1983 through 1987 the final grade distribution was (141 students) A 23\%, B 41\%, C 29\%, D 5\%.

For the years 1991 through 1995 the distribution (104 students) was: A 22\%, B 49\%, C 20\%. D $5 \%$. The course during these years included labs, written reports, term papers, oral reports and multiple choice tests with some essay questions. The pool of questions, excepting those lab related, was the same for both time periods.

Also the student background has changed over years. In the 80's most were technicians employed by a nuclear power plant project. The 90's group was a mixture of students with varied work experience or none at all. The same instructor has taught all these years. It is his opinion that the final student level of knowledge of materials has remained constant.

\section{APPENDIX I ENTRANCE REQUIREMENTS}

Recent high school graduates: 
8 semesters English

2 semesters geometry

2 semesters algebra

2 semesters laboratory science

Adults 3 or more years out of high school:

2 semesters algebra

2 semesters geometry

high school diploma

\section{APPENDIX II COURSE OUTLINE}

1. properties of materials

2. atoms and molecules

3. Unit cells, slip, dislocations

4. Equilibrium diagrams

5. Iron and steel

6. Heat treating of steel

7. Alloy steels

8. Non ferrous metals

9. Age hardening

10. Plastics

11. Ceramics

\section{APPENDIX III TYPICAL TEXTS}

1. Budinski, K. Engineering Materials - Properties and Selection Englewood Cliffs, New Jersey Prentice Hall 5th ed. 1996

2. Jacobs, J. and Kilduff, T. Engineering Materials Technology Upper Saddle River, New Jersey Prentice Hall 3rd ed. 1997

\section{BIOGRAPHY}

Ed Gohmann is an Associate Professor of Mechanical Engineering Technology at Purdue University Programs at New Albany, Indiana. He is self taught in Engineering Materials and has been teaching Introductory Materials I for 19 years. He has a Master of Engineering in Mechanical Engineering and a Bachelors in Aeronautical Engineering. 